\title{
Effect of Acrylamide on Ovaries of Female Albino Rats and Possible Protective Role of Vitamin E
}

\author{
MOHAMED A. DOSUKY, M.D.*; SALWA M. OUIES, M.D.** and NOHA A.R. FOUDA, M.Sc.** \\ The Department of Human Anatomy \& Embryology, Faculties of Medicine, Al-Minia* and Sohag** Universities
}

\begin{abstract}
Background: Acrylamide (ACR) is a chemical substance with a very wide range of uses and it accounts for one of the major health concern and one of the most important contaminants occurring in foods heated at high temperatures so human exposure to ACR is high. Vitamin $\mathrm{E}$ is the most important lipid-soluble vitamin presents in the nature and one of the basic vitamins in biological systems and plays a vital role in many physiological processes.
\end{abstract}

Aim of Study: To investigate the Potential protective effects of Vitamin E on Acrylamide induced ovarian damage in female albino rats through histological examination by light microscope.

Material and Methods: This study was conducted in Human Anatomy and Embryology Department in Sohag University during 2019 forty-five female virgin albino rats weighing 180-300g were used and randomly divided into three equal groups: Control group; ACR group was given 10 $\mathrm{mg} / \mathrm{kg}$ body weight of acrylamide for by oral gavage for 3 weeks; the third group was given ACR at a dosage of 10 $\mathrm{mg} / \mathrm{kg} / \mathrm{d}$, and vitamin $\mathrm{E}$ at a dose of $100 \mathrm{mg} / \mathrm{kg}$ body weight for 3 weeks orally then sacrificed by cervical dislocation Ovaries were excised for light microscopic study and morphometric study.

Results: Oral administration of ACR induced marked cystic ovarian changes, degenerative changes in zona pellucida, Granulosa cells and oocytes detected by light microscope this study reported that supplementation of a diet with Vit E provided antioxidant defense against the toxicity of ACR in ovary.

Conclusions: These results concluded that acrylamide combined with vitamin $\mathrm{E}$ in comparison with acrylamide induced less ovarian damage and this protective effect might be due to the antioxidant activity of Vit E.

Key Words: Acrylamide - Vitamin E.

Correspondence to: Dr. Mohamed A. Dosuky, The Department of Human Anatomy \& Embryology, Faculty of Medicine, Al-Minia University

\section{Introduction}

DETERMINATION of ovarian toxicity is very important for the evaluation of the safety of drugs and chemicals, because any abnormities in the ovaries indicates an impairment of the female reproductive capacity, results from morphological analysis of the ovaries [1].

Acrylamide (ACR) is an important chemical compound that has been reported to be present in plant material like potatoes, and rice. Many diseases are associated with ACR due to its high exposure as in drinking water, inhalation, skin absorption and occupational exposure, direct exposure to acrylamide may result from ingestion of high-carbohydrate foods prepared at high temperatures such as potato crisps, Acrylamide formed in foods, in frying not in boiling [2], after exposure, ACR accumulates rabidly in the blood than in any other tissue. It rapidly distributed to all tissues and transformed into Glycidamide (GA), a more toxic form than ACR; it is toxic to the reproductive system, neurotoxic, genotoxic, and carcinogenic [3]. It was indicated that such effects of ACR is due to oxidative stress, hence occurred infertility [4].

To overcome oxidative stress, antioxidants and plant phenolics are considered as the chemo protective agents against oxidative stress-related diseases. Vit E (Anti-infertility Vitamin) is a powerful antioxidant, capable of protecting the cells and tissues against oxidative stress-induced damage through increasing the antioxidant capacity by scavenging of free radicals [5].

In addition to the direct antioxidant capacity, effects on cardiovascular system are beneficial to health due to the anti-inflammatory, anti-throm- 
botic, and anti-hypertensive actions, infertility continues to increase every day so the present study, investigated the effects of acrylamide and vitamin $\mathrm{E}$ on ovarian tissues of adult female rats [6].

\section{Material and Methods}

\section{Material:}

Acrylamide was purchased from El Gomhorya Company, Egypt as white powder Vitamin E was purchased as soft gelatin capsules from pharco pharmaceuticals Company, Egypt. Each capsule contained $400 \mathrm{mg}$ of vitamin $\mathrm{E}$.

Animals: Forty-five adult virgin female rats weighed 180-300gm, each were used in the present study. All animals were housed under the same conditions and allowed food and water. Rats were randomly divided into three equal groups, given the treatment via oral gavage. All animals were treated in accordance with the guide for the care and use of laboratory animals approved by the Research Ethical Committee of the Faculty of Medicine, Sohag University, Sohag, Egypt.

- Control group: Received $0.5 \mathrm{ml}$ of saline orally for 3 weeks.

- Acrylamide-treated group: Were given ACR by oral gavage at a dosage of $10 \mathrm{mg} / \mathrm{kg} / \mathrm{d}$, dissolved in distilled water, for 3 weeks) [2].

- ACR + Vit. E treated group: Were given ACR by oral gavage at a dosage of $10 \mathrm{mg} / \mathrm{kg} / \mathrm{d}$, dissolved in distilled water, for 3 weeks and will receive orally by gavage vitamin $\mathrm{E}$ at a dose of $100 \mathrm{mg} / \mathrm{kg}$ body weight for 3 weeks [2].

At the end, the animals were sacrificed by cervical dislocation. Specimens from the ovaries were subjected to light microscopic and morphometric studies.

\section{Light microscopic study:}

Specimens were fixed in $10 \%$ formalin, processed and embedded in paraffin. Serial sections (5 microns) were prepared and subjected to hematoxylin and eosin stain [5].

\section{Morphometric methods:}

Morphometric study was performed on $\mathrm{H}$ \& $\mathrm{E}$ sections of different experimental groups (control and treated groups) by counting the number of ovarian follicles. Primordial follicles were counted at a magnification 400, other types of follicles were counted at a magnification 100 [7].

\section{Statistical analysis:}

The ovarian weight and the number of different types of follicles of the control and treated groups were recorded in the tables; results were expressed as mean value \pm standard deviation. The data were statistically analyzed using the independent $t$-test. A probability value of $p>0.05$ is considered nonsignificant, $p 0.05(*)$ is considered significant difference, $p 0.01\left(^{* *}\right)$ is considered high significant difference, $p 0.001(* * *)$ is considered very high significant difference, statistical significance was accepted at $p<0.05[8]$.

\section{Results}

Control group: Histological study Figs. (1-4):

Specimens obtained from the control rats and stained with $\mathrm{H} \& \mathrm{E}$ showed normal structure of the ovary in the form of outer cortex containing the follicles and central medulla. The cortex showed primordial follicle with flat follicular cells, primary follicles with cuboidal follicular cells with zona pellucida around the oocyte, antral follicles with cavities between the follicular cells, graffian follicles with antrum, many corpus luteum were composed of mature lutein cells with clear vacuolated eosinophilic cytoplasm and large nucleus with open chromatin arranged in cords around sinusoids. Some Atritic follicle found with dark piknotic detached granulosa cells in the follicular antrum.

ACR-group: Histological study Figs. $(5,6)$ :

Oral administration of acrylamide induced cystic ovarian changes in the form of destruction of the oocyte like deformity and degeneration, dark piknotic detached granulosa cells with darkly stained nuclei disorganization of both zona pellucid and corona radiate layers, apparent regression of follicles with fluid filled cavities with increased number of atritic (cystic) follicles, with decreased number of the growing follicles, Hemorrhage in the cortex, Medulla showed vaculations wide distended blood vessels, with inflammatory infiltrations.

Combined ACR + Vit E Group: Histological study Figs. $(7,8)$ :

Examination of this group showed restoration of the normal shape and architecture of the ovary irregular surface, the cortex containing all the stages of the follicles, restoration the number of corpus luteum, less cystic follicles, medulla showed congested vessels, with less inflammatory infiltration, no vaculations, cortex showed hemorrhage. 


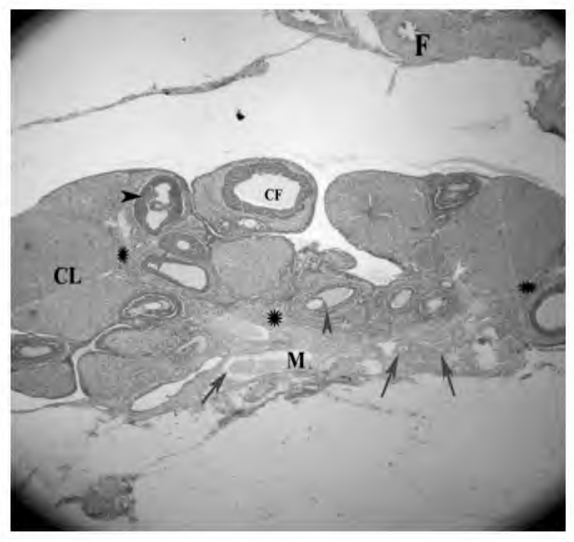

Fig. (1): A photomicrograph of section through the ovary of control rat (group 1) showing; cortex containing Corpus Leutum (CL), Cystic Follicles (CF), primary follicle (green arrow head), secondary follicle (red arrow head), graffian follicle (blue arrow head), antral follicle (black arrow head), stroma cells (stars), Medulla (M) blood vessels (blue arrows) and Fallopian tube (F). (H \& E X40).

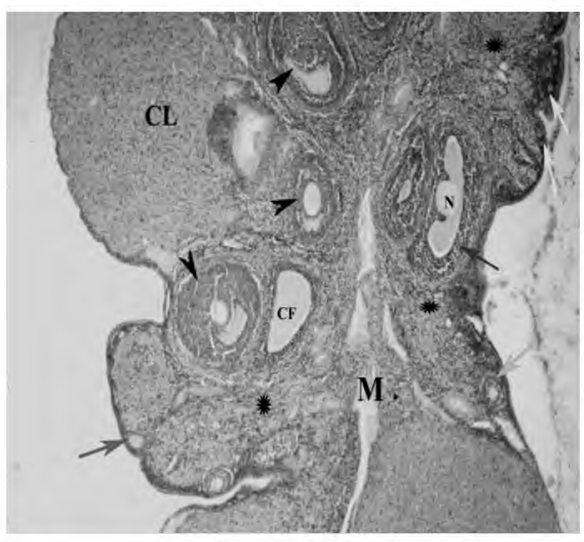

Fig. (2): A magnification of the previous photomicrograph of section through the ovary of control rat (group 1) showing, primordial follicles (white arrow) cortical stroma (stars), ovarian medulla (m), primary follicle (red arrow), secondary follicle (green arrow), graffian follicle (blue arrow) showing large Nucleus (N), antral follicles (head arrows), Cystic Follicle (CF) and Corpus Luteum (CL) (H \& E X100).

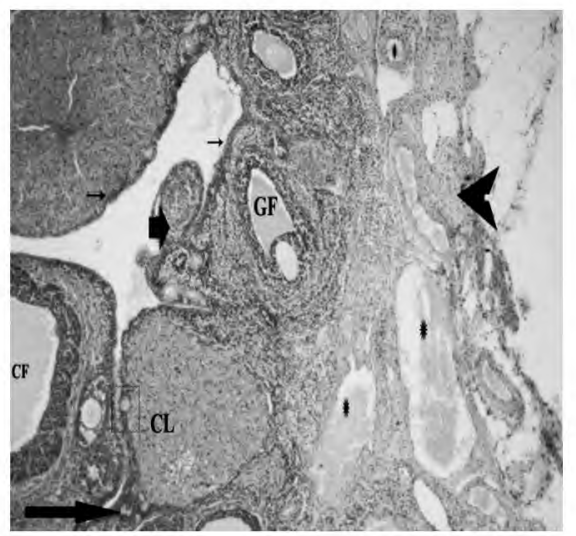

Fig. (3): A photomicrograph of section through the ovary of control rat (group 1) showing; connective tissue of the medulla (head arrow) with multiple blood vessels (stars), Cystic Follicle (CF), Graffian Follicle antrum (GF), surface epithelium (thin arrows), tangential view and the enclosed oocytes are not included in the section (thick arrow) (H \& E $\mathrm{X} 100)$.

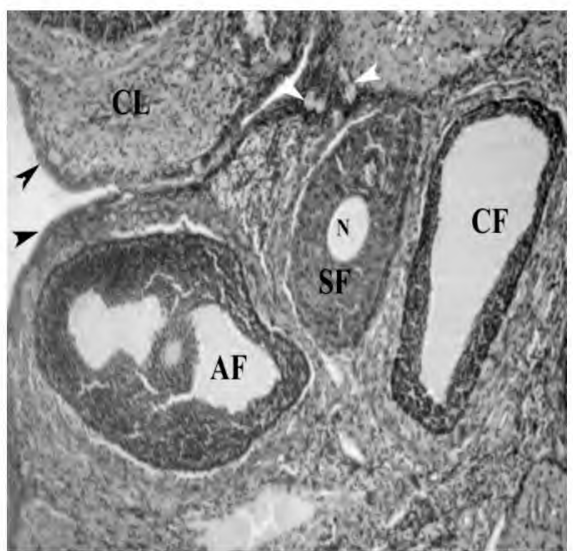

Fig. (4): A photomicrograph of section through the ovary of control rat (group 1) showing; Cystic Follicle (CF), Corpus Luteum (CL), Antral Follicle (AF), surface epithelium (black arrow heads), primordial follicles (white arrow heads) and vesicular nucleus of oocyte of the secondary follicle $(\mathrm{N})(\mathrm{H}$ \& E X200).

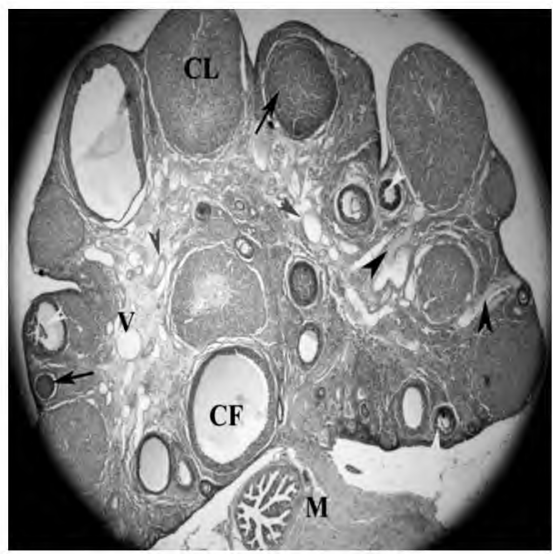

Fig. (5): A photomicrograph of section through the ovary of acrylamide treated rat (group 2) showing; many Cystic Follicles (CF), piknotic of granulosa cell (arrows) vaculations in the medulla (v), degenerated oocyte and disorganization of both zona pellucid and corona radiate layers (green arrow heads) increased vasculature in medulla (blue arrow heads) and hemorrhages (black arrow heads). (H \& E X40).

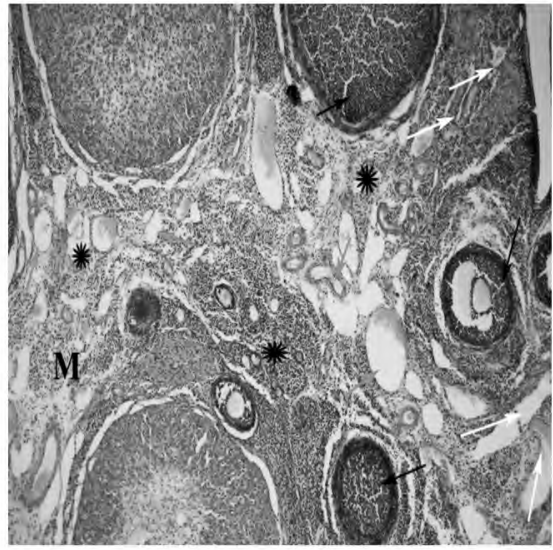

Fig. (6): Magnification of the previous photomicrograph of the ovary of acrylamide treated rat (group 2) showing apparent regression of follicles with degenerated granulosa cells (black arrows), marked inflammatory infiltrations (stars) and Vaculations (V) of the Medulla (M) a with dilated blood vessels (red arrows) hemorrhages in the stroma (white arrows) (H \& E X200). 


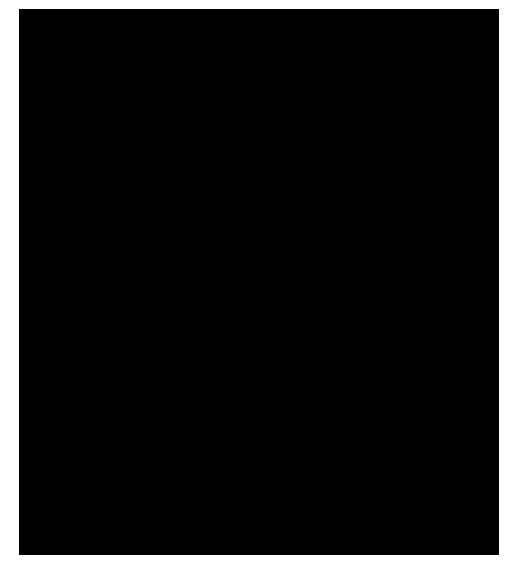

Fig. (7): A photomicrograph of the ovary of Vit E and acrylamide treated rat (group 3) showing different stages of follicles with primordial follicles (black arrows), less Cystic Follicle (CF), many Corpus Luteum (CL) and antral follicle (red arrows) graffian follicle (arrow head) hemorrhage in Medulla (M) (H \& E X40).

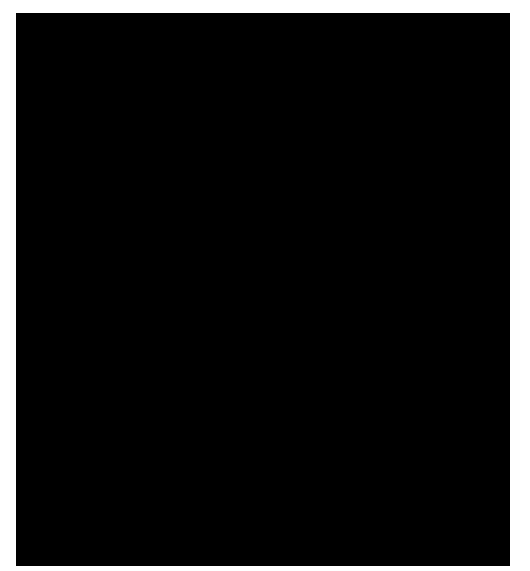

Fig. (8): Magnification of the previous photomicrograph of the ovary of Vit E and acrylamide treated rat (group 3) showing inflammatory infiltration in stroma (stars) primordial follicles (red arrow), Corpus Luteum (CL) primary follicles (black arrow head) and secondary follicle (blue arrow head) (H \& E X200).

Morphometric and statistical results (Table 1), Histogram (1):

The mean ovarian weight of adult rats treated with ACR for 3 weeks showed high significant decrease as compared with adult control rats. The mean ovarian weight of adult rats treated with ACR and Vit E for 3 weeks showed a non-significant decrease as compared with adult control rats.

The morphometric studies showed a very high significant decrease in the number of healthy growing follicles and a very high significant decrease in corpora Lutea and a very high significant increase in cystic follicles in the ACR-treated group compared with the controls, rats treated with ACR and Vit $\mathrm{E}$ for 3 weeks showed a significant decrease in the total number of follicles and in the number of corpus luteum but non-significant increase in atretic follicles compared to control group.

Table (1): Descriptive statistics for ovarian weight in adult groups, numbers of atretic follicles, corpus luteum, and total count of the follicles.

\begin{tabular}{llll}
\hline Parameters & Control & ACR & ACR + Vit. E \\
\hline • Ovary weight $(\mathrm{mg})$ & $94.94 \pm$ & $82.80 \pm$ & $93.46 \pm$ \\
& 8.94 & $10.08 * *$ & 9.32 \\
- Total number of follicles & $4,849.60 \pm$ & $2,905.80 \pm$ & $4,642.00 \pm$ \\
& 234.14 & $243.44 * * *$ & $222.97 *$ \\
- Number of corpora & $518.47 \pm$ & $265.13 \pm$ & $471.40 \pm$ \\
leutea & 4.96 & $91.42^{* * *}$ & $33.49 *$ \\
- Number of the atretic & $258.20 \pm$ & $404.87 \pm$ & $250.20 \pm$ \\
follicles & 6.14 & $51.11 * * *$ & 16.20 \\
\hline
\end{tabular}

Values are mean $\pm \mathrm{SD} ; p>0.05$---> non-significant, $p 0.05(*)$ ----> significant difference, $p 0.01(* *)$----> high significant difference, $p 0.001(* * *)$----> very high significant difference.
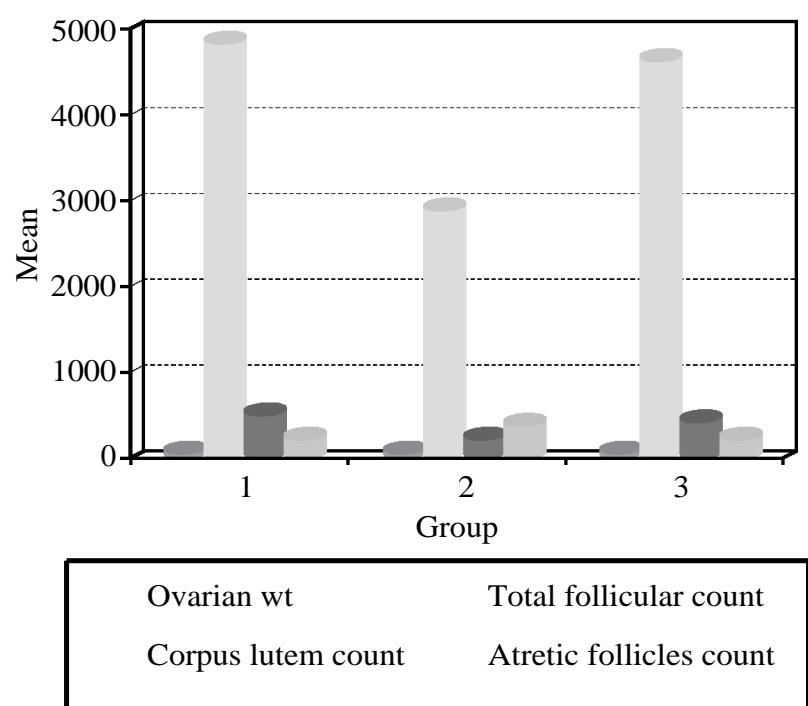

Histogram (1): Showing the mean of ovarian weights, total follicular count, corpus luteum and atretic follicle counts of the rats in control and experimental groups.

\section{Discussion}

Acrylamide (ACR) is one of the major environmental public health problems [9]. In the present study, it was observed that oral administration of of ACR produced histological changes in reproductive system in females [10]. Natural dietary antioxidants have possible protective powers against toxicity induced by dietary contaminants [11].

In this study, evaluation of the protective effect of Vit $\mathrm{E}$ against ovarian damage and histological changes induced by ACR in rats was done, animals received ACR showed ovarian damage in the form of cystic changes with significant decrease in ovarian weights, total follicular count an increased atretic follicle count with hemorrhage and inflam- 
matory infiltrations, these results are in agreement with Duan et al., [8] and ALKarim et al., [9] and Mahmood et al., [1] who reported that rats exposured to oral acrylamide showed obvious reduction of the mature follicles with underdevelopment of other follicles.

These results are not in agreement with Rawi et al., [12] who reported that ACR is not affecting the ovary significantly with presence of mature follicles and corpus luteum in ovarian sections after 28-day treatment with ACR. Researchers that investigated the effects of ACR on reproductive toxicity in the reproductive tissues reported that it decrease reduced glutathione levels, led to DNA damage, it was indicated that such toxic effects of ACR due to imbalance between the production of Reactive Oxygen Species (ROS) and antioxidant capacity increases oxidative stress [3]. In the present study, the light microscopic and the morphometric results revealed that rats treated with ACR and Vit E showed improvement in the ovarian damage caused by ACR these results are in agreement with Erdemli et al., [2] assured that Vitamin E is a powerful antioxidant as protects the cell membrane from oxidation by reacting with free radicals produced in the lipid peroxidation chain reaction and prevents the propagation reaction [13]. Al-Serwi and Ghoneim., [5] reported that administration of the Vit E with ACR resulted in amelioration in the histological and biochemical parameters. Vitamin $\mathrm{E}$ is considered a major chain-breaking antioxidant and prevents oxygen molecules from being too reactive, also helps in cell signaling during chemical information transfer from one cell to another, or across different structures inside the cell [14].

\section{Conclusion:}

Concomitant supplying of Vit E to ACR treated rats reduced the ovarian damage caused by acrylamide so VIT $E$ has potential protective role against ACR induced reproductive toxicity.

\section{References}

1- MAHMOOD S.A.F., AMIN K., RAHMAN H.S. and OTHMAN H.H.: The Pathophysiological Effects of Acrylamide in Albino Wister Rats, International Journal of Medical Research \& Health Sciences, 5, 7: 42-8, 2016.

2- ERDEMLI M.E., ERDEMLI Z., TURKOZ Y., BAG H.G. and SELAMOGLU Z.: The effects of acrylamide and vitamin $\mathrm{E}$ administration during pregnancy on adults' ovarian tissue: An experimental Study, Annals of Medical Research Original Article, 26 (9): 1856-60, 2019.
3- GHORBEL I., ELWEJ A., FENDRI N., MNIF H., JAMOUSSI K., BOUDAWARA T., KAMOUN N.G. and ZEGHAL N.: Olive oil abrogates acrylamide inducednephrotoxicity by modulating biochemical and histological changes in rats, Renal Failure, DOI: 10.1080/0886022X. 2016.1256320, 2016.

4- RIBOLDI B.P., VINHAS Á.M. and MOREIRA J.D.: Risks of dietary acrylamide exposure: A systematic review Food Chemistry, 157: 310-22, 2014.

5- AL-SERWI R.H. and. GHONEIM F.M.: J. Micro. Ultrastruct. The impact of vitamin $\mathrm{E}$ against acrylamide induced toxicity on skeletal muscles of adult male albino rat tongue: Light and electron microscopic study Jul.Sep., 3 (3): 137-47, 2015.

6- HEGAZY A.A., MORSY M.M., SHEHATA M.A. and AGAGA R.A.: Effect of Administration of Acrylamide and Possible Protective Role of Vitamin E on Postnatal Rat Liver Structure. J. Embryol. Stem. Cell Res., 2 (2): 000114, 2018.

7- ALI A.A., EL-SEIFY G.H., HALA, EL HAROUN M. and MONA ABD EL MAWLA MOHAMMED SOLIMAN: Effect of monosodium glutamate on the ovaries of adult female albino rats and the possible protective role of green tea, Menoufia Medical Journal, 27: 793$800,2014$.

8- WEI Q., LI J., LI X., ZHANGA L. and SHI F.: Reproductive toxicity in acrylamide-treated female mice, Reproductive Toxicology, 46: 121-8, 2014.

9- DUAN X., WANG Q.C., CHEN K.L., ZHU C.C., LIU J. and SUN S.C.: Acrylamide toxic effects on mouse oocyte quality and fertility in vivo. Scientific Reports, 5: 11562, 2015.

10- ALKARIM S., ELASSOULI S., ALI S., AYUOB N. and ELASSOULI Z.: Effects of low dose acrylamide on the rat reproductive organs structure, fertility and gene integrity. Asian Pacific Journal of Reproduction, 4: 17987, 2015.

11- HAMDY S.M., SHABAAN A.M., LATIF A.K.M.A., ABDEL-AZIZ A.M. and AMIN A.M.: Protective effect of Hesperidin and Tiger nut against Acrylamide toxicity in female rats. Experimental and Toxicologic Pathology, 2017.

12- RAWI S.M., MARIE M.A.S., FAHMY S.R. and. ELABIED S.A.: Hazardous effects of acrylamide on immature male and female rats African Journal of Pharmacy and Pharmacology, Vol. 6 (18): 1367-86, 2012.

13- HELAL E.G.E, TAHA N.M., MOHAMED A.M. and ABU-TALEB H.M.: Ameliorative Effect of Vitamin E on Oxidative Stress Induced by Bisphenol A in Female Albino Rats, The Egyptian Journal of Hospital Medicine, 65: 474-8, 2016.

14- PACKER L., WEBER S.U. and RIMBACH G.: Molecular aspects of alpha-tocopherol antioxidant action and cell signaling. J. Nutr., 131: 369S-373S, 2001. 


\section{تآثير عقار الآكريلاميد على المبايض لإناث الفئران البيضاء

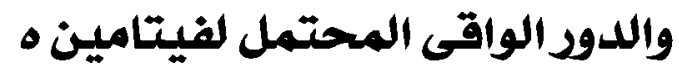

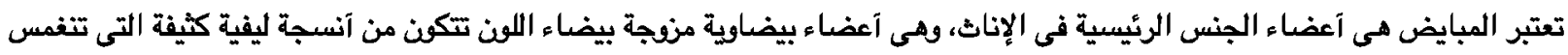

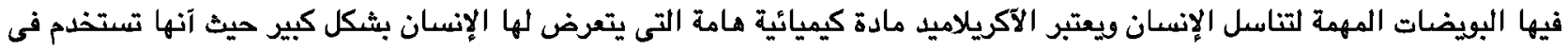

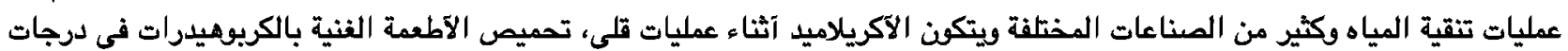

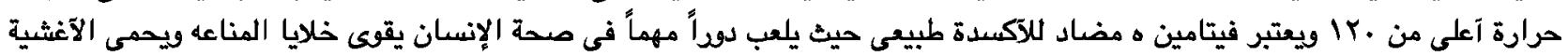
الخلوية ولذلك يحافظ على السلامة الخلوية والوظيفية.

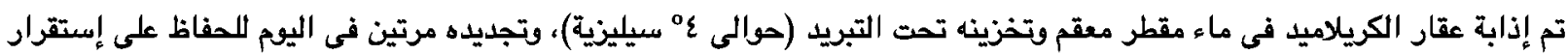

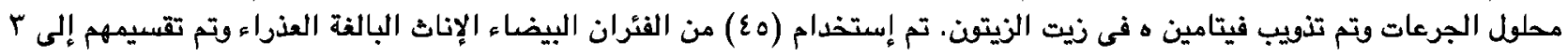

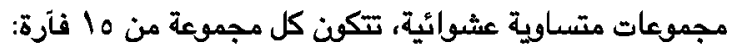

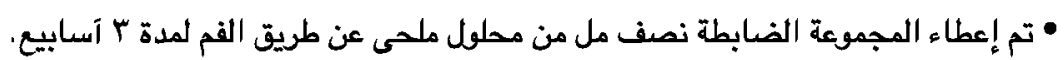

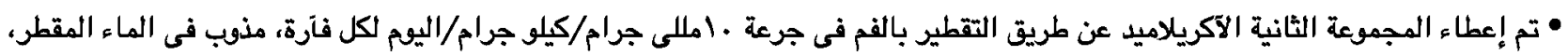
لمدة بآسابيع.

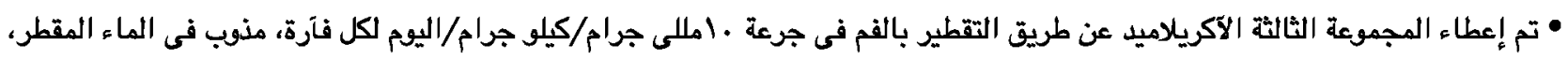

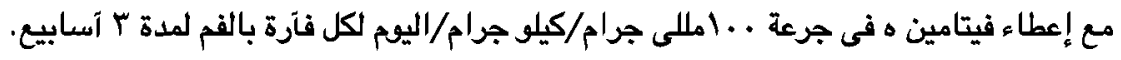

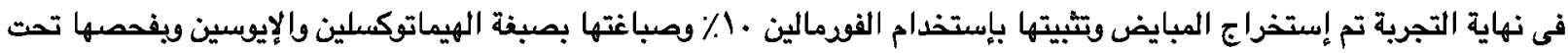

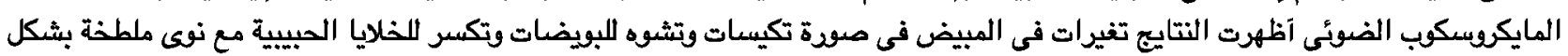

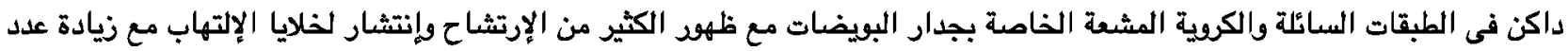

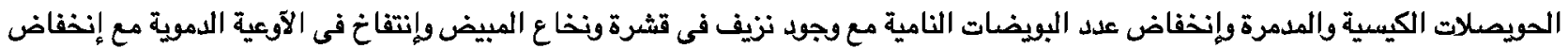

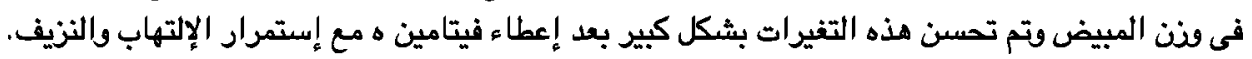

